\title{
Peertechz
}

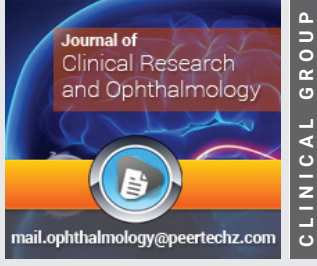

\section{Six steps for a successful phacoemulsification in hard}

\section{cataracts}

\author{
S Venkatesh, Mavnika* and Shruti P Hedge
}

Department of Ophthalmology, Shri Sathya Sai Medical College \& Research Institute, India

Received: 30 January, 2021

Accepted: 18 May, 2021

Published: 19 May, 2021

*Corresponding authors: Dr. Mavnika, Department of Ophthalmology, Shri Sathya Sai Medical College \& Research Institute, India, Tel: 91 7708347469;

E-mail:mavnika.doc@gmail.com

Keywords: Phacoemulsification; Hard cataract; Power modulation

https://www.peertechzpublications.com

Check for updates

\section{Abstract}

Phacoemulsification in rock-hard cataracts is always challenging for the phaco surgeon. Patient presenting with hard cataract is common in rural and suburban areas. In such situations phaco surgeons face higher incidence of significant complication like endothelial cell loss, posterior capsular rupture, zonular dialysis. By judicious use of the appropriate technology like perfect power modulations, enhanced fluidics, adequate OVDs usage better results can be achieved in these cases. In this short communication we have put together six salient steps that would help the surgeon in achieving successful phacoemulsification in hard cataracts.

\section{Introduction}

A true measure of a phaco surgeon expertie is the appearance of clear cornea on the first postoperative day following phacoemulsification in grade 3-4 nuclear sclerotic cataract. These hard cataracts have considerable mass and consume significant phaco energy and phaco time, both of which have deleterious effect on corneal endothelium. Therefore certain clear principles should be followed and these well defined principles should be adhered by every phaco surgeon for successful phacoemulsification.

We present 6 steps which when carefully followed can enhance the rate of success of phacoemulsification in hard cataracts. These steps would really help any phaco surgeon to achieve crystal clear cornea after surgery in hard cataracts.

\section{The six steps for successful phacoemulsification in a hard cataract are}

Pupillary dilatation: Well dilating pupil is an important prerequisite to carry on hastle free phaco in patients with hard cataracts. Meticulous preoperative evaluation should be done to know the maximum mydriasis in these patients. Due to nuclear fragments hitting the iris "Break-through" pupillary shutdown is common in these cases. Use of epinephrine in irrigating solution is recommended to avoid this \& to keep the pupil dilated throughout the surgery. In poorly dilating pupil as in case of pseudoexfoliation or in floppy iris, pupil expansion devices like iris hooks and Malyugin rings can be used [1,2].

Staining \& sizing of capsulorhexis: Capsulorhexis in rock hard cataract is challenging because of the colour of the hard nucleus and faint red fundal glow, staining the anterior capsule with trypan blue $0.06 \%$ can facilitate capsulorhexis (CCC). Capsulorhexis the marking is essentially important to make a perfect CCC. $5.5-6.5 \mathrm{~mm}$ rhesis is done for a rockhard cataract for easy phaco removal of nuclear fragments. A visible rhexis margin can avoid inadvertent damage during nuclear phacoemulsification [3].

Hydrodiseection at multiple sites with small aliquots: Hydrodissection should be performed with utmost care because posterior capsule tend to be very thin in hard cataracts and rapid pressure build up can blowout the posterior capsule. Hydrodissection should be performed gently at multiple site and giving gentle tap on the nucleus after every manipulation to avoid pressure raise [4].

Meticulous \& generous use of OVDs: Perks of using a dispersive viscoelastics: Protection of corneal endothelium is important key in any phaco surgery. This can be achieved with the use of dispersive ocular viscoelastic devices because they retain in the anterior chamber and coat the corneal endothelim unlike the cohesive OVD's which gets removed easily. Use of Arshinoff's softshell technique is another way to protect the corneal endothelium from phaco damage [5]. 
Quadrant-fill-quadrant removal: After every quadrant removal anterior chamber should be filled with OVD's as a layer. Be cautious not to overload the chamber with the ocular viscoelastics.

Phaco power modulations: While impaling the nucleus in order to start the crack, its better to start with the multiburst mode, in which phaco power is delivered in small packets of specific duration, separated by an interval of $1.2 \mathrm{sec}$ that gradually decrease in a linear fashion by pressing the foot pedal in position 3 till they become continuous. Fragment removal a pulse mode is preferred over the micropulse because of the duty cycle of 50 percent and is therefore more effective in breaking down hard cataracts. In some machines like the SOVEREIGN compact that has the variable whitestar power modulation which can be used for both impaling and removing the nuclear fragments.

Use of direct chop technique: Direct chop technique of nuclear fragmentation has the advantage of using lesser phaco energy \& in hard cataract this comes really handy. In very hard cataracts a central crater can be created before initiating the chop. A sharp tipped chopper is employed \& every attempt should be made to prevent going to the periphery while chopping the hard nucleus.

\section{Conclusion}

We have highlighted 6 critical steps for achieving successful phacoemulsification in hard cataracts. Along with this suggestion it is also important that the surgeon should have a significant control over their non-dominant hand in order to perform a good chop technique. In addition a phaco surgeon should not embark the phaco surgery without achieving a successful hands on. In order to achieve a good success rate a phaco surgeon should have attempted atleast 25-50 cases previously. In addition compromising situations like Zonular dialysis, non -dilating pupil, pseudoexfoliation with hard cataract management should be done with meticulous care.

\section{References}

1. Malyugin B (2017) Cataract surgery in small pupils. Indian J Ophthalmol 65 1323-1328 . Link: https://bit.ly/2S23Kpp

2. Chang DF (2008) Use of Malyugin pupil expansion device for intraoperative floppy-iris syndrome: results in 30 consecutive cases. J Cataract Refract Surg 34: 835-841. Link: https://bit.ly/3yhp1fs

3. Melles GR, de Waard PW, Pameyer JH, Beekhuis WH (1999) Trypan blue capsule staining to visualize the capsulorhexis in cataract surgery. J Cataract Refract Surg 25: 7-9. Link: https://bit.ly/3ykmqBk

4. Yeoh R (1996) The 'pupil snap' sign of posterior capsule rupture with hydrodissection in phacoemulsification. $\mathrm{Br} \mathrm{J}$ Ophthalmol 80: 486. Link: https://bit.ly/3foStYs

5. Storr-Paulsen A, Nørregaard JC, Farik G, Tårnhøj J (2007) The influence of viscoelastic substances on the corneal endothelial cell population during cataract surgery: a prospective study of cohesive and dispersive viscoelastics. Acta Ophthalmol Scand 85: 183-187. Link: https://bit.ly/3tXZftt
Discover a bigger Impact and Visibility of your article publication with

Peertechz Publications
Highlights

* Signatory publisher of ORCID

- Signatory Publisher of DORA (San Francisco Declaration on Research Assessment)

- Articles archived in worlds' renowned service providers such as Portico, CNKI, AGRIS, TDNet, Base (Bielefeld University Library), CrossRef, Scilit, J-Gate etc.

* Journals indexed in ICMJE, SHERPA/ROMEO, Google Scholar etc.

- OAI-PMH (Open Archives Initiative Protocol for Metadata Harvesting)

* Dedicated Editorial Board for every journal

* Accurate and rapid peer-review process

* Increased citations of published articles through promotions

- Reduced timeline for article publication

Submit your articles and experience a new surge in publication services (https://www.peertechz.com/submission). 